\title{
Analysis of a Four-Firm Competition Based on a Generalized Bounded Rationality and Different Mechanisms
}

\author{
S. S. Askar $(\mathbb{D})^{1,2}$ and A. Al-khedhairi $(\mathbb{D})^{1}$ \\ ${ }^{1}$ Department of Statistics and Operations Researches, College of Science, King Saud University, P.O. Box 2455, \\ Riyadh 11451, Saudi Arabia \\ ${ }^{2}$ Department of Mathematics, Faculty of Science, Mansoura University, Mansoura 35516, Egypt
}

Correspondence should be addressed to S. S. Askar; s.e.a.askar@hotmail.co.uk

Received 3 April 2019; Accepted 19 May 2019; Published 29 May 2019

Academic Editor: Dimitrios Stamovlasis

Copyright (c) 2019 S. S. Askar and A. Al-khedhairi. This is an open access article distributed under the Creative Commons Attribution License, which permits unrestricted use, distribution, and reproduction in any medium, provided the original work is properly cited.

In this paper, the Caputo derivative with fractional orders is suggested to model a competition among four competing firms. The proposed economic model that describes this competition is constructed based on a generalization of the traditional bounded rationality. In this generalization, we study the influence of memory parameter on the complex behavior of the model. Memory means that we not only take into account the changes in quantities at a current time, but also study the changes occurring in the quantities during an interval of time. For simplicity, it is assumed that the degree of memory is described by one parameter during that interval. The properties of the proposed model such as stability of equilibria, bifurcation, and chaos are studied. Furthermore, we introduce and study the cooperation that may take place among the four firms using Keeney-Raiffa approach.

\section{Introduction}

The process of memory is an important aspect that is considered when studying some dynamical systems. It is considered as an application of the fractional derivatives and has been studied in different applications such as biology, physics, and economy as in [1-3]. Fractional derivative has some unusual characteristics on which all types of noninteger orders derivatives should be satisfied. For instance, the derivative of the product of two functions (Leibniz rule) and the composition of two functions (Chain rule) are violated under fractional derivatives. Game theory is considered as an important tool that is used to model competitions arising among human beings. John Von Neumann and Oskar Morgenstern were the first pioneers who introduced the game theory as a mathematical model describing such competition in [4]. Based on this work, a sequence of contributions in this direction has been emerged. For instance, Nash in [5] has introduced the model of bargaining. The game of nperson has been discussed by Shapley in [6]. The readers who are interested in the first contributions are advised to see [7-9].
Oligopoly games constitute another contribution introduced after the first works by Neumann and Oskar. Recently, researchers are interested in studying the dynamic characteristics of such games. Literature has included many works of such games whose dynamic behavior is very complex and includes important phenomena such as bifurcation and chaos. For instance, the differentiation of consumers between products has been introduced and investigated in [10]. Rationality and heterogeneous expectations that may arise in models of economy have been studied in [11] by Hommes. Expectations mean that the behaviors adopted by a firm may be naive, rational, or local approximation mechanism. Those different types of expectations have been studied in literature (see [12-18]). In this paper, we adopt and focus on the bounded rationality approach and Puu's mechanism.

Bounded rationality approach has been intensively used in literature. In this introduction we highlight some important works that have adopted this mechanism. For instance, dynamic studies for a Cournot duopoly game under differentiated products with bounded rationality firms have been discussed in [19]. Some dynamic characteristics of a nonlinear duopoly game with price competition and horizontal 
product differentiation have been investigated in [20]. In [21] a class of congestion games has been introduced using the bounded rationality approach and its dynamic characteristics have been analytically investigated.

Puu's mechanism is also another approach that has been used to model economic games in literature. It is used in [22] to investigate the dynamic behavior of a Cournot game. This approach has some advantages; e.g., it is a realistic mechanism. It needs only the firms to know their profits and quantities produced in two periods of time. Other applications of this mechanism can be found in $[23,24]$.

The discrete fractional-order dynamical system provides more realistic mathematical modeling than continuous dynamical systems for some specific cases. For example, discrete-time models of economy become more appropriate than the continuous time models when the players numbers are small, or when actions and decisions occur at discrete times or within certain intervals of time. Realistic modeling of Cournot quadropoly games requires the involvement of memory effects in mathematical models representing the games. The dynamical behaviors of a proposed fractionalorder version of Cournot quadropoly games are analytically and numerically investigated in this paper.

It is important to attract the attention of interested readers to some applications in social and economical systems which incorporate interplay and competitions among agents. For instance, Kahneman's bounded rationality approach has been reviewed in [25]. In [26], a social model of spontaneous self-organization generating criticality and resilience, called Self-Organized Temporal Criticality, has been proposed. The approach of Kahneman's bounded rationality requires the use of fractional derivatives in time, in the same way as Caputo fractional derivatives in our current paper. The fractional calculus has been adopted to simulate either subdiffusion or superdiffusion in the absence of memory of the events occurring at earlier times in [27]. Other studies that follow this line of research can be found in literature; see $[28,29]$.

In this paper, we modify the so-called bounded rationality approach using fractional derivatives. Therefore, the fractional bounded rationality is introduced and is used to formulate a discrete dynamic system that describes the competition among four firms (sometimes it is called quadropoly game). Although the price function used in this competition is simple, the dynamic system constructed is complicated because it contains a gamma function which makes the analytical calculations very hard. This makes us use deep numerical simulations to investigate the stability of the Nash point of the system. In addition, we formulate a four-firm game based on Puu's mechanism to compare its obtained results with those given by the fractional bounded rationality. Furthermore, a cooperative situation that may be carried out among the four firms is suggested. The Keeney-Raiffa function is used to construct this cooperation.

In brief, the paper presents four sections. In Section 1 an introduction is given. Section 2 introduces the fractional bounded rationality approach with its corresponding dynamic system. In this section some analytical and numerical simulations around the Nash point and its stability are given. In Section 3 we study the Puu's system and its stability. In Section 4 we introduce and study the stability of cooperation scenario. Finally, some conclusions are delivered.

\section{A Fractional Bounded Rationality Oligopolistic Model}

The model considered here consists of four firms whose main decision variable is the quantity produced by each firm. We refer to the quantity by $q_{i}, i=1,2,3,4$. For a simple reason, we here assume that the four firms supply the market with homogeneous commodities; besides, they bear the same marginal cost that is denoted by $c$. In addition, we assume that the firms adopt the simple price function $p$ that can be expressed by the total supply $Q$ as follows:

$$
\begin{aligned}
& p=a-Q, \\
& Q=\sum_{i=1}^{4} q_{i}
\end{aligned}
$$

where the parameter $a$ refers to a constant price in case firms do not provide the market with quantities. Thus, the profit of each firm is given by the following.

$$
\pi_{i}=\left(a-\sum_{i=1}^{4} q_{i}-c\right) q_{i}, \quad i=1,2,3,4
$$

Our main interest in this paper is to study the dynamics of an oligopoly game under a generalized form of bounded rationality. The description of traditional bounded rationality is briefly given in [30-32]. This generalized form of the bounded rationality mechanism is as follows:

$$
x_{t+1}=x_{t}+k D^{\alpha}\left(\Phi\left(x_{t}\right)\right)
$$

where $x_{t}$ refers to the strategic variable adopted by a firm. It may be quantity, price, or mixed type of variables. In this paper, it represents the quantity produced by a firm. The parameter $k$ is an important one when studying such games. It refers to the speed of adjustment of each firm. The constant $\alpha$ is restricted on the interval $\alpha \in(0,1)$. This parameter may refer to the memory of firms that take into account not only the change of quantity from current price (price at current time) but also all the changes of quantities for some interval of time. $D^{\alpha}\left(\Phi\left(x_{t}\right)\right)$ represents the fractional derivative of the function $\Phi\left(x_{t}\right)$ which in this paper refers to the firm's profit. According to Caputo in [33], this derivative can be given by

$$
D^{\alpha}(\Phi(v))=\frac{1}{\Gamma(n-\alpha)} \int_{0}^{v}(v-s)^{n-\alpha-1} \Phi^{(n)}(s) d s
$$

where $n \in \mathbb{Z}^{+}$and $\Gamma($.) is the Euler's Gamma function. $\Phi^{(n)}(s)$ refers to the $n^{\text {th }}$-order derivative of $\Phi(s)$. We will use the following definition.

Definition 1. For $\alpha \in \mathbb{R}^{+}$, let $n$ be the nearest integer greater than $\alpha$; the Caputo fractional derivative of order $\alpha>0$ with $n-1<\alpha<n$ of the power function $f(t)=t^{p}$ for $p \geq 0$ and $t>0$ is given by

$$
D^{\alpha} t^{p}=\frac{\Gamma(p+1)}{\Gamma(p-\alpha+1)} t^{p-\alpha} .
$$


For more discussion about fractional derivative one can refer to any book in fractional calculus such as [33] by Podlubny.

Recently, the main efforts exerted toward nonlinear theory in the economic discipline aim at modeling appropriate oligopoly games to describe and investigate the actual operation of the game. Although the importance of oligopoly game and its variants have attracted economists and mathematicians since the time of its proposition till present time, memory effects in discrete-time oligopoly games have not been addressed yet. The main motivation of this paper is to introduce the more realistic fractional-order discrete version of Cournot oligopoly games and to address the problem of studying the nonlocal properties induced by fractional-order derivatives. Using (2),(3), (4), and (6) the following discrete dynamical system is obtained.

$$
\begin{aligned}
& q_{1, t+1} \\
& =q_{1, t} \\
& +\frac{k q_{1, t}^{1-\alpha}}{\Gamma(2-\alpha)}\left[a-c-2 q_{1, t}-\left(q_{2, t}+q_{3, t}+q_{4, t}\right)\right], \\
& q_{2, t+1} \\
& =q_{2, t} \\
& +\frac{k q_{2, t}^{1-\alpha}}{\Gamma(2-\alpha)}\left[a-c-2 q_{2, t}-\left(q_{1, t}+q_{3, t}+q_{4, t}\right)\right], \\
& q_{3, t+1} \\
& =q_{3, t} \\
& +\frac{k q_{3, t}^{1-\alpha}}{\Gamma(2-\alpha)}\left[a-c-2 q_{3, t}-\left(q_{1, t}+q_{2, t}+q_{4, t}\right)\right],
\end{aligned}
$$

$$
J=\left[\begin{array}{cccc}
1-2 k\left(\frac{a-c}{5}\right)^{1-\alpha} & -k\left(\frac{a-c}{5}\right)^{1-\alpha} & -k\left(\frac{a-c}{5}\right)^{1-\alpha} & -k\left(\frac{a-c}{5}\right)^{1-\alpha} \\
-k\left(\frac{a-c}{5}\right)^{1-\alpha} & 1-2 k\left(\frac{a-c}{5}\right)^{1-\alpha} & -k\left(\frac{a-c}{5}\right)^{1-\alpha} & -k\left(\frac{a-c}{5}\right)^{1-\alpha} \\
-k\left(\frac{a-c}{5}\right)^{1-\alpha} & -k\left(\frac{a-c}{5}\right)^{1-\alpha} & 1-2 k\left(\frac{a-c}{5}\right)^{1-\alpha} & -k\left(\frac{a-c}{5}\right)^{1-\alpha} \\
-k\left(\frac{a-c}{5}\right)^{1-\alpha} & -k\left(\frac{a-c}{5}\right)^{1-\alpha} & -k\left(\frac{a-c}{5}\right)^{1-\alpha} & 1-2 k\left(\frac{a-c}{5}\right)^{1-\alpha}
\end{array}\right]
$$

whose characteristic polynomial takes the form

$$
\begin{aligned}
f(\gamma) & =\lambda^{4}+A_{1} \lambda^{3}+A_{2} \lambda^{2}+A_{3} \lambda+A_{4}, \\
A_{1} & =-4+8 k\left(\frac{a-c}{5}\right)^{1-\alpha}, \\
A_{2} & =6\left[1-k\left(\frac{a-c}{5}\right)^{1-\alpha}\right]\left[1-3 k\left(\frac{a-c}{5}\right)^{1-\alpha}\right], \\
A_{3} & =4\left[4 k\left(\frac{a-c}{5}\right)^{1-\alpha}-1\right]\left[1-k\left(\frac{a-c}{5}\right)^{1-\alpha}\right]^{2}, \\
A_{4} & =\left[1-5 k\left(\frac{a-c}{5}\right)^{1-\alpha}\right]\left[1-k\left(\frac{a-c}{5}\right)^{1-\alpha}\right]^{3}
\end{aligned}
$$

$$
\begin{aligned}
& q_{4, t+1} \\
& \quad=q_{4, t} \\
& \quad+\frac{k q_{4, t}^{1-\alpha}}{\Gamma(2-\alpha)}\left[a-c-2 q_{4, t}-\left(q_{1, t}+q_{2, t}+q_{3, t}\right)\right]
\end{aligned}
$$

This system is the dynamic case of the proposed competition that occurs among four competed firms. It is a nonlinear system and admits only two fixed points, $e_{0}=(0,0,0,0)$ and ne $=((a-c) / 5,(a-c) / 5,(a-c) / 5,(a-c) / 5)$. However, the first point $e_{o}$ does not have any meaning in the economic competition; we just study here its stability.

Proposition 2. The fixed point $e_{0}$ is unstable.

Proof. The Jacobian matrix at $e_{0}$ takes the following form:

$$
J=\left[\begin{array}{llll}
1 & 0 & 0 & 0 \\
0 & 1 & 0 & 0 \\
0 & 0 & 1 & 0 \\
0 & 0 & 0 & 1
\end{array}\right]
$$

whose characteristic polynomial is as follows.

$$
f(\gamma)=\gamma^{4}-4 \gamma^{3}+6 \gamma^{2}-4 \gamma+1
$$

It is easy to check that there are two negative principal minors of the above polynomial, and hence according to Routh-Hurwitz criteria the fixed point $e_{0}$ is unstable.

Proposition 3. The fixed point ne is asymptotically stable under certain conditions.

Proof. The Jacobian matrix at ne takes the following form:

and then Hurwitz matrix becomes as follows.

$$
\left[\begin{array}{cccc}
A_{1} & 1 & 0 & 0 \\
A_{3} & A_{2} & A_{1} & 1 \\
0 & A_{4} & A_{3} & A_{2} \\
0 & 0 & 0 & A_{4}
\end{array}\right]
$$

For ne to be asymptotically stable, the principal minors of the above matrix should satisfy the conditions: $A_{1}>$ $0, A_{1} A_{2}-A_{3}>0$, and $A_{1} A_{2} A_{3}-A_{1}^{2} A_{4}-A_{3}^{2}>0$.

2.1. Numerical Simulation. Numerical simulation is carried out to support and get some insights about the system's 


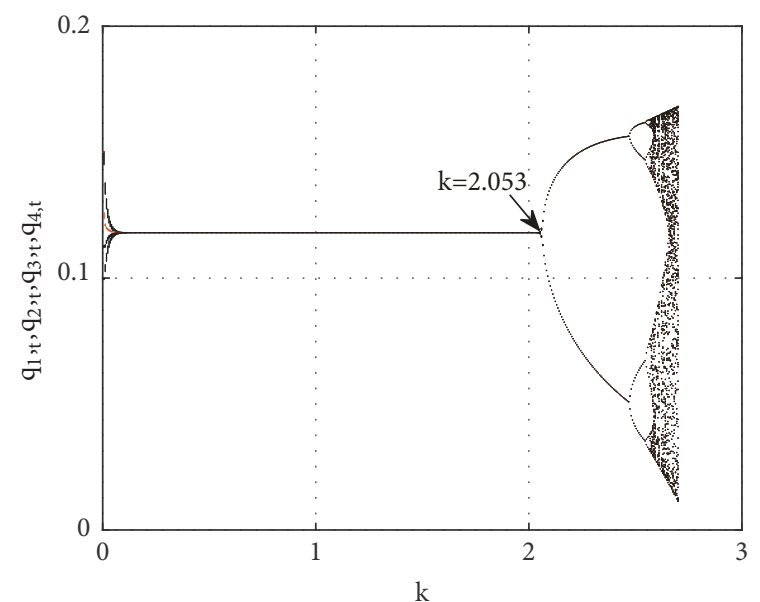

(a)

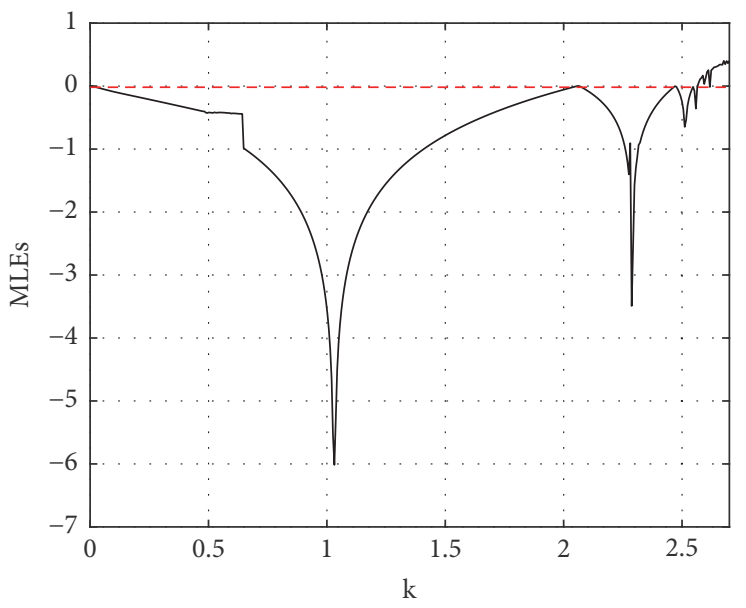

(c)

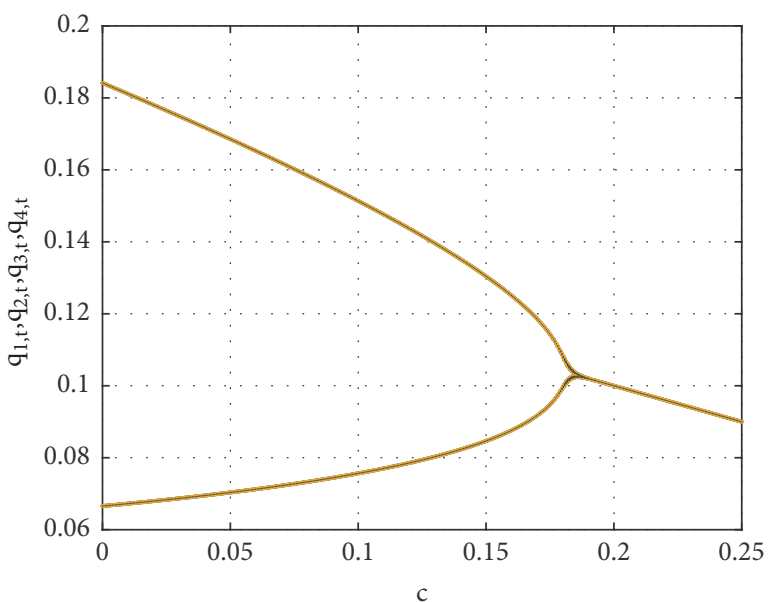

(b)

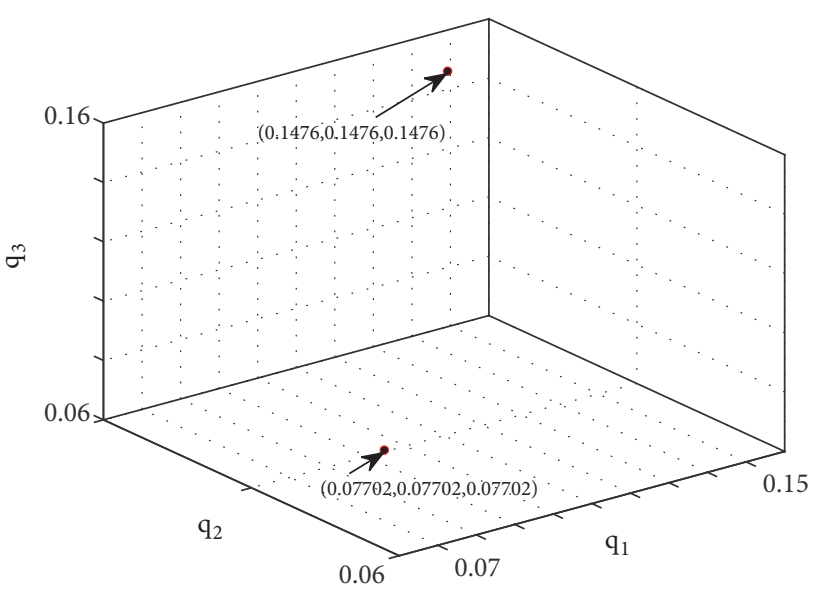

(d)

Figure 1: (a) Bifurcation diagram of system (6) with respect to $k$ at $\left(a, c, \alpha, q_{0,1}, q_{0,2}, q_{0,3}, q_{0,4}\right)=(0.7,0.11,0.5,0.19,0.15,0.13,0.11)$. (b) Bifurcation diagram of system (6) with respect to $c$ at $\left(a, k, \alpha, q_{0,1}, q_{0,2}, q_{0,3}, q_{0,4}\right)=(0.7,2.2,0.5,0.19,0.15,0.13,0.11)$. (c) Maximum Lyapunov exponents with respect to $k$ at $\left(a, c, \alpha, q_{0,1}, q_{0,2}, q_{0,3}, q_{0,4}\right)=(0.7,0.11,0.5,0.19,0.15,0.13,0.11)$. (d) Phase portrait of the period 2-cycle of system (6) at $\left(a, c, k, \alpha, q_{0,1}, q_{0,2}, q_{0,3}, q_{4}\right)=(0.7,0.11,0.5,0.19,0.15,0.13,0.11)$.

behavior and to investigate the stability of the fixed point ne. We provide local and global analysis about the stability of this point. We divide the numerical simulation here into two parts according to the memory parameter $\alpha$. Two different values for $\alpha$ are studied, $\alpha=1 / 2$ and $\alpha=3 / 4$. For $\alpha=1 / 2$, let us take the values $a=0.7, c=0.11$, and the initial quantities are $q_{0,1}=0.19, q_{0,2}=0.15, q_{0,3}=0.13, q_{0,4}=0.11$. Figure $1(\mathrm{a})$ shows that the stability of ne point is not affected by any values of the parameter $k$ till it goes to 2.053 . Therefore any value of $k$ up to the rough value $k=2.053$ will cause a period doubling bifurcation and hence the system becomes chaotic due to chaos. This is confirmed in Figure 1(c) where the maximum Lyapunov exponent shows that at this point of the parameter $k$ the shape of the MLEs changes. The bad impact of the cost parameter on the system's behavior is also shown in Figure 1(b). The simulation tests the cost parameter for several values of the parameter $k$ and we conclude that the cost always has that influence. In Figure 1(d) we present the phase space of the period 2-cycle at $\left(a, c, k, \alpha, q_{0,1}, q_{0,2}, q_{0,3}, q_{4}\right)=$
$(0.9,0.11,2.2,0.5,0.19,0.15,0.13,0.11)$. For this period cycle, the basin of attraction is given in Figure 2(a). The black region refers to the basin of unfeasible trajectories. The $2 \mathrm{D}$ bifurcation diagram, which is also called Arnold tongues or mode-locking tongues, is plotted in Figure 2(b). It shows the periodicity regions in the parameter space $(k, c)$. Increasing the value of the parameter $a$ causes a decrease in the stability region of the equilibrium point as shown in Figure 2(c). Our simulation analysis shows that the value of $a=0.7$ gives a better region of stability for the equilibrium point. The simulation is tested for different values of that parameter below 0.7 and the result was not good as in the case where $a=0.7$. We have given here only the result when $a=1$ in Figure 2(c). In addition, for different values for the parameter $a$, the phase space for different period cycles and chaotic behavior are depicted in Figures 2(d), 3(a), 3(b), and 3(c).

In Figure 3(d), we study another case where the value of the memory parameter $\alpha=3 / 4$. In this case we take $\Gamma(1.25)=$ 0.90640. The bifurcation diagram is shown in Figure 3(d). 


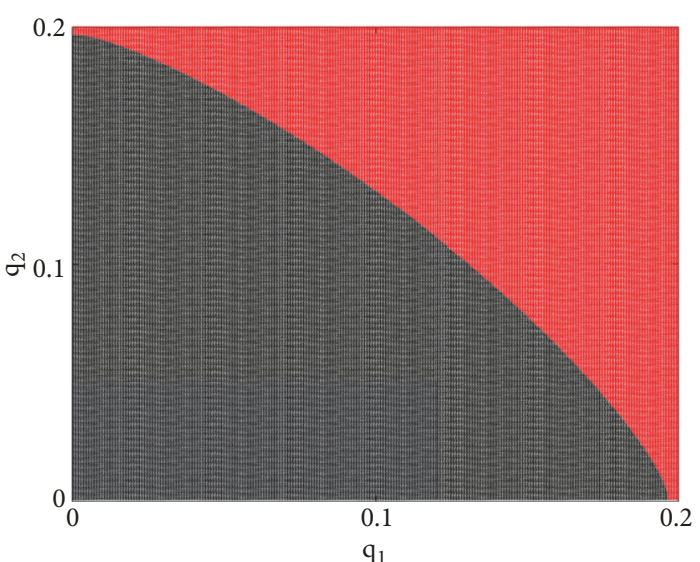

(a)

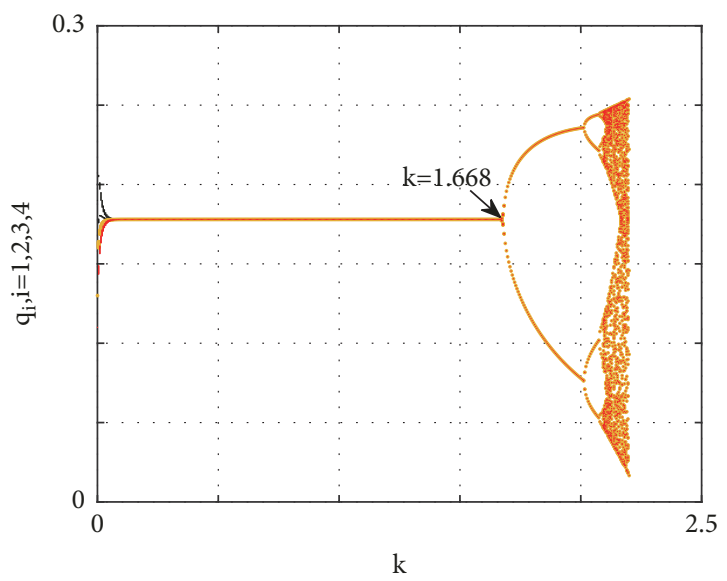

(c)

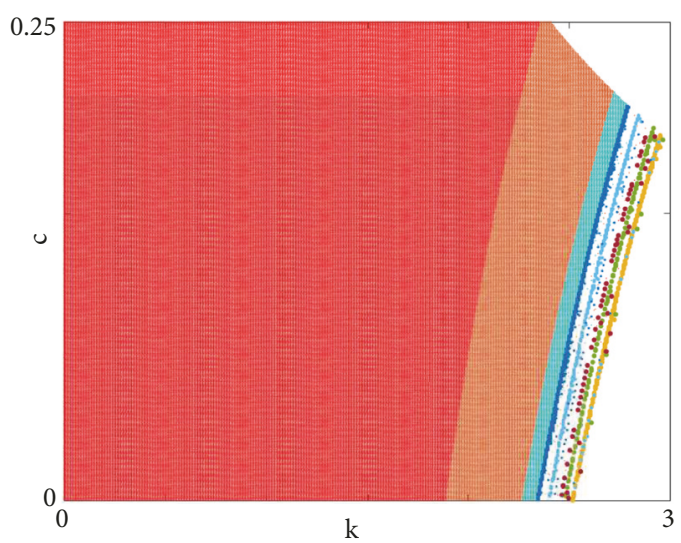

(b)

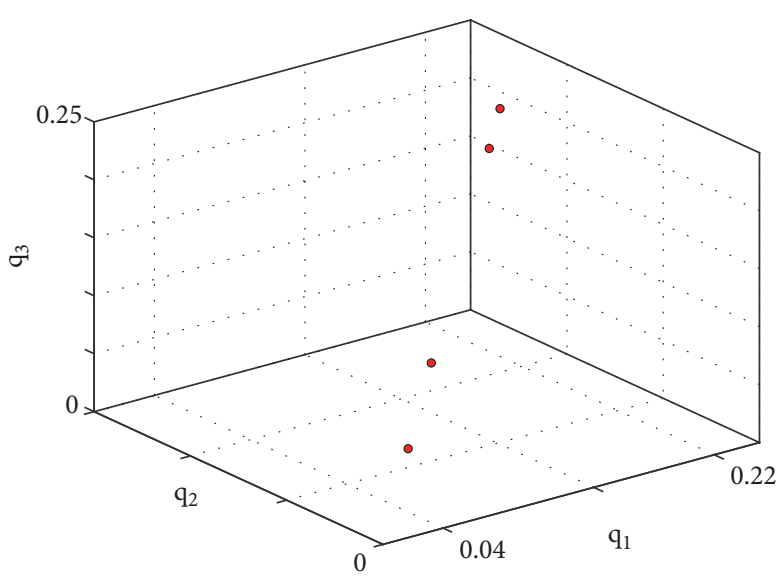

(d)

Figure 2: (a) The basin of attraction of the period 2-cycle at $\left(a, c, k, \alpha, q_{3}, q_{4}\right)=(0.7,0.11,2.2,0.5,0.13,0.11)$. (b) $2 \mathrm{D}$ bifurcation in the $(k, c)$ parameter plane at $\left(a, \alpha, q_{0,1}, q_{0,2}, q_{0,3}, q_{0,4}\right)=(0.7,0.11,2.2,0.5,0.19,0.15,0.13,0.11)$. (c) Bifurcation diagram of system (6) with respect to $k$ at $\left(a, c, \alpha, q_{0,1}, q_{0,2}, q_{0,3}, q_{0,4}\right)=(1,0.11,0.5,0.19,0.15,0.13,0.11)$. (d) Phase portrait of the period 4-cycle of system (6) at $\left(a, c, k, \alpha, q_{0,1}, q_{0,2}, q_{0,3}, q_{4}\right)=(0.9,0.11,2.2,0.5,0.19,0.15,0.13,0.11)$.

It is clear that the equilibrium point is asymptotically stable for values of the parameter $k<0.6429$. This bifurcation diagram confirms the obtained results given in Proposition 2 regarding the local stability of the point ne. It also confirms that the region of the stability of ne is less than the one obtained when $\alpha=1 / 2$. The corresponding Lyapunov exponent of this bifurcation diagram is given in Figure 4(a). This makes us investigate more the complex behavior of system (6). Figures 4(b) and 4(c) present the coexisting of period 2-cycle and period 4-cycle, respectively. The basin of attraction of the stable period 2-cycle and period 4cycle is given in Figures 4(d) and 5(a). In Figure 5(b) a 2D bifurcation diagram in the $(k, c)$ parameter plane which is obtained at the parameter values $\left(a, \alpha, q_{0,1}, q_{0,2}, q_{0,3}, q_{0,4}\right)=$ $(0.625,0.75,0.19,0.15,0.13,0.11)$ showing periodicity region corresponding to different period cycles. Finally, we observe that a decrease in the value parameter $a$ will reduce the stability region of the ne point and this is given in Figure 5(c), and its corresponding Lyapunov exponent is depicted in Figure 5(d).

\section{Puu's Game}

Puu's mechanism has been recently used for modeling and studying the complex characteristics of discrete dynamic economic systems. It depends on two things: the profit at two periods of time, $t-1$ and $t$, besides the firms' quantities at the same two periods of time. For some details on this mechanism and its advantages and drawbacks we advise the readers to see [34]. The mechanism takes the following form.

$$
q_{i, t+1}=q_{i, t}+\frac{\pi_{i, t}-\pi_{i, t-1}}{q_{i, t}-q_{i, t-1}}, \quad i=1,2,3,4
$$

Suppose that the four competed firms start the competition with approximately the same quantities at the previous two time periods. This means that $q_{1, t} \approx q_{2, t} \approx q_{3, t} \approx q_{4, t}$ and $q_{1, t-1} \approx q_{2, t-1} \approx q_{3, t-1} \approx q_{4, t-1}$; then by using (2) and (12), the following system is obtained.

$$
\begin{aligned}
& q_{1, t+1}=q_{1, t}+k\left[a-c-4\left(q_{1, t}-q_{1, t-1}\right)\right], \\
& q_{2, t+1}=q_{2, t}+k\left[a-c-4\left(q_{2, t}-q_{2, t-1}\right)\right],
\end{aligned}
$$




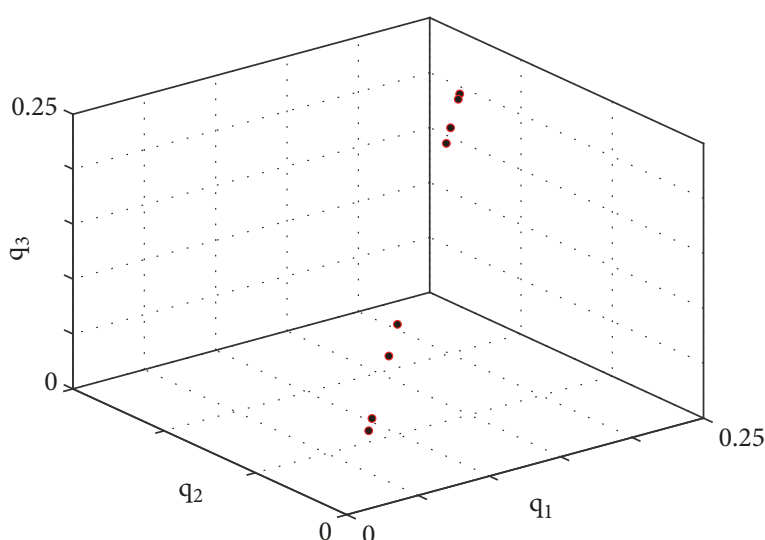

(a)

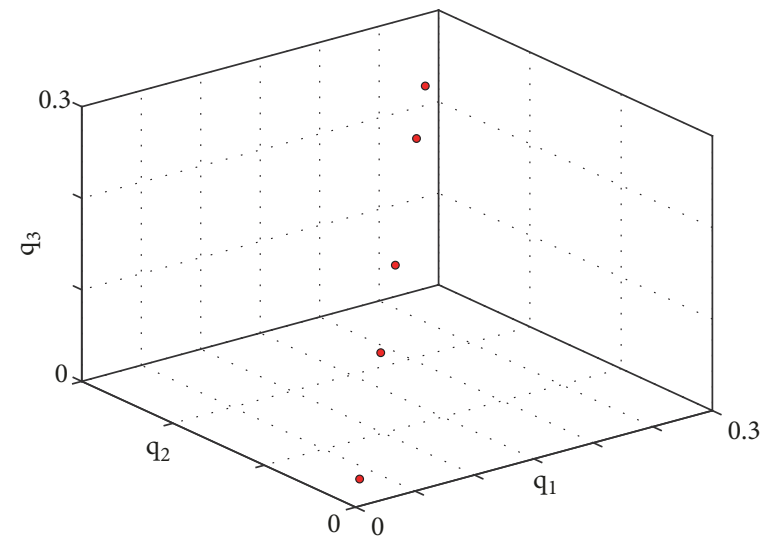

(c)

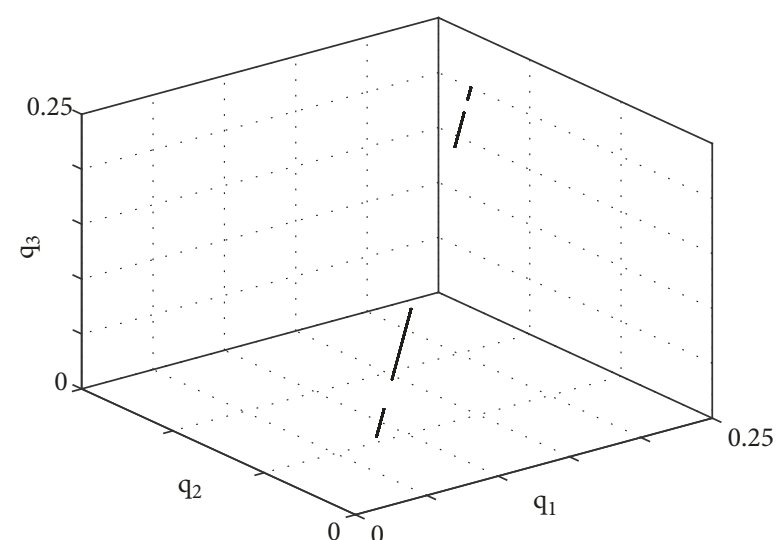

(b)

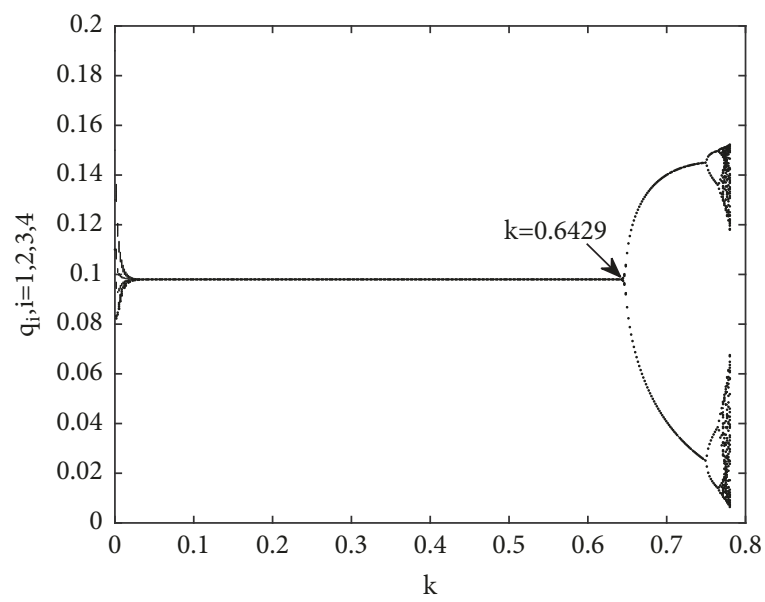

(d)

Figure 3: (a) Phase portrait of the period 8-cycle of system (6) at $\left(a, c, k, \alpha, q_{0,1}, q_{0,2}, q_{0,3}, q_{4}\right)=(0.91,0.11,0.5,0.19,0.15,0.13,0.11)$. (b) Chaotic behavior of system (6) at $\left(a, c, k, \alpha, q_{0,1}, q_{0,2}, q_{0,3}, q_{4}\right)=(0.92,0.11,0.5,0.19,0.15,0.13,0.11)$. (c) Phase portrait of the period 5-cycle of system (6) at $\left(a, c, k, \alpha, q_{0,1}, q_{0,2}, q_{0,3}, q_{4}\right)=(1,0.11,0.5,0.19,0.15,0.13,0.11)$. (d) Bifurcation diagram of system (6) with respect to $k$ at $\left(a, c, \alpha, q_{0,1}, q_{0,2}, q_{0,3}, q_{0,4}\right)=(0.625,0.11,0.75,0.19,0.15,0.13,0.11)$.

$$
\begin{aligned}
& q_{3, t+1}=q_{3, t}+k\left[a-c-4\left(q_{3, t}-q_{3, t-1}\right)\right], \\
& q_{4, t+1}=q_{4, t}+k\left[a-c-4\left(q_{4, t}-q_{4, t-1}\right)\right]
\end{aligned}
$$

The above system admits only one fixed point, $n e_{1}=((a-$ c) $/ 8,(a-c) / 8,(a-c) / 8,(a-c) / 8)$.

Proposition 4. The equilibrium point ne ${ }_{1}$ is unstable.

Proof. Let $x_{i, t}=q_{i, t-1}, i=1,2,3,4$; then system (13) can be rewritten in the following form.

$$
\begin{aligned}
& q_{1, t+1}=q_{1, t}+k\left[a-c-4\left(q_{1, t}-x_{1, t}\right)\right], \\
& q_{2, t+1}=q_{2, t}+k\left[a-c-4\left(q_{2, t}-x_{2, t}\right)\right], \\
& q_{3, t+1}=q_{3, t}+k\left[a-c-4\left(q_{3, t}-x_{3, t}\right)\right], \\
& q_{4, t+1}=q_{4, t}+k\left[a-c-4\left(q_{4, t}-x_{4, t}\right)\right], \\
& x_{1, t+1}=q_{1, t},
\end{aligned}
$$

$$
\begin{aligned}
& x_{2, t+1}=q_{2, t}, \\
& x_{3, t+1}=q_{3, t},
\end{aligned}
$$$$
x_{4, t+1}=q_{4, t}
$$

The Jacobian matrix is given as follows:

$$
\left[\begin{array}{cccccccc}
1-4 k & 0 & 0 & 0 & 4 k & 0 & 0 & 0 \\
0 & 1-4 k & 0 & 0 & 0 & 4 k & 0 & 0 \\
0 & 0 & 1-4 k & 0 & 0 & 0 & 4 k & 0 \\
0 & 0 & 0 & 1-4 k & 0 & 0 & 0 & 4 k \\
1 & 0 & 0 & 0 & 0 & 0 & 0 & 0 \\
0 & 1 & 0 & 0 & 0 & 0 & 0 & 0 \\
0 & 0 & 1 & 0 & 0 & 0 & 0 & 0 \\
0 & 0 & 0 & 1 & 0 & 0 & 0 & 0
\end{array}\right],
$$




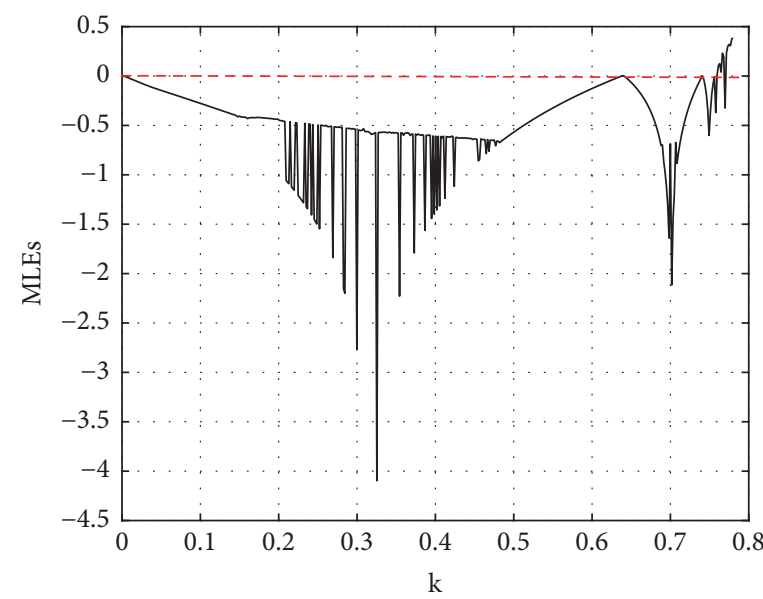

(a)

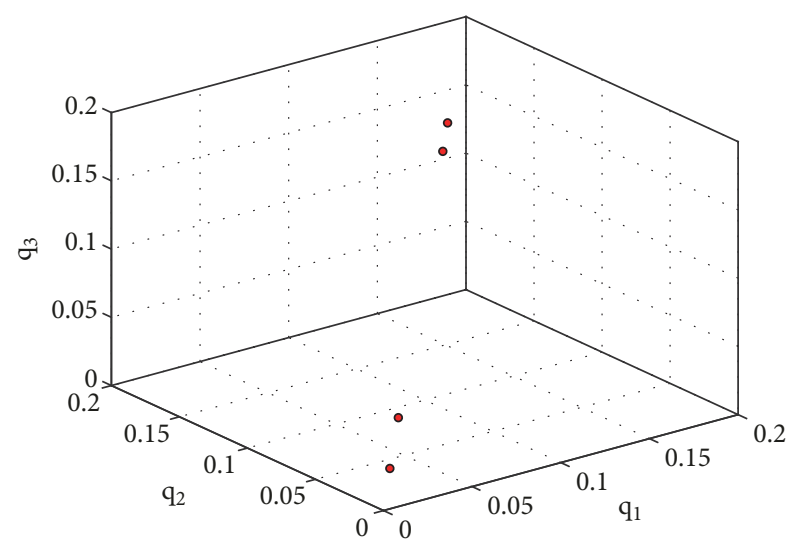

(c)

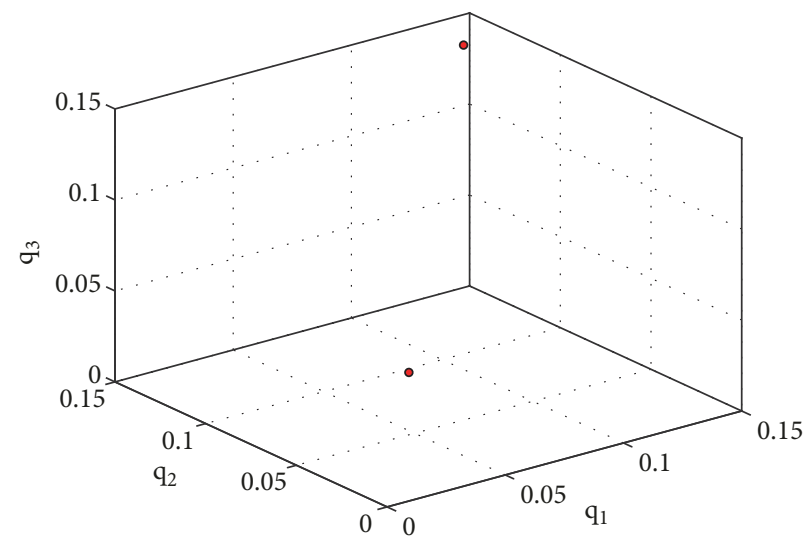

(b)

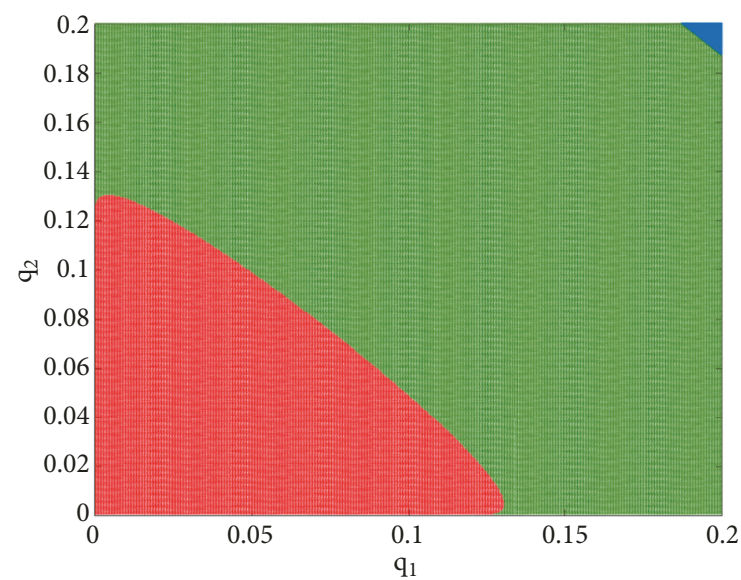

(d)

Figure 4: (a) Maximum Lyapunov exponents with respect to $k$ at $\left(a, c, \alpha, q_{0,1}, q_{0,2}, q_{0,3}, q_{0,4}\right)=(0.625,0.11,0.75,0.19,0.15,0.13,0.11)$. (b) Phase portrait of the period 2-cycle of system (6) at $\left(a, c, k, \alpha, q_{0,1}, q_{0,2}, q_{0,3}, q_{4}\right)=(0.625,0.11,0.7,0.75,0.19,0.15,0.13,0.11)$. (c) Phase portrait of the period 4-cycle of system (6) at $\left(a, c, k, \alpha, q_{0,1}, q_{0,2}, q_{0,3}, q_{4}\right)=(0.625,0.11,0.75,0.75,0.19,0.15,0.13,0.11)$. (d) The basin of attraction of the period 2-cycle at $\left(a, c, k, \alpha, q_{3}, q_{4}\right)=(0.625,0.11,0.7,0.75,0.13,0.11)$.

and then the characteristic polynomial becomes as follows.

$$
\begin{aligned}
f(\zeta)= & \zeta^{8}+\Lambda_{1} \zeta^{7}+\Lambda_{2} \zeta^{6}+\Lambda_{3} \zeta^{5}+\Lambda_{4} \zeta^{4}+\Lambda_{5} \zeta^{3} \\
& +\Lambda_{6} \zeta^{2}+\Lambda_{7} \zeta+\Lambda_{8} \\
\Lambda_{1}= & 4(-1+4 k) \\
\Lambda_{2}= & 2[3+16 k(3 k-2)] \\
\Lambda_{3}= & 4(-1+4 k)\left(1-20 k+16 k^{2}\right) \\
\Lambda_{4}= & 1+64 k(2 k-1)\left(1-7 k+2 k^{2}\right) \\
\Lambda_{5}= & -16 k(-1+4 k)\left(1-20 k+16 k^{2}\right) \\
\Lambda_{6}= & 32 k^{2}\left(3-32 k+48 k^{2}\right) \\
\Lambda_{7}= & -265 k^{3}(-1+4 k) \\
\Lambda_{8}= & 265 k^{4}
\end{aligned}
$$

Now Hurwitz matrix becomes as follows.

$$
\left[\begin{array}{cccccccc}
\Lambda_{1} & \Lambda_{3} & \Lambda_{5} & \Lambda_{7} & 0 & 0 & 0 & 0 \\
1 & \Lambda_{2} & \Lambda_{4} & \Lambda_{6} & 0 & 0 & 0 & 0 \\
0 & \Lambda_{1} & \Lambda_{3} & \Lambda_{5} & \Lambda_{8} & 0 & 0 & 0 \\
0 & 1 & \Lambda_{2} & \Lambda_{4} & \Lambda_{6} & \Lambda_{8} & 0 & 0 \\
0 & 0 & \Lambda_{1} & \Lambda_{3} & \Lambda_{5} & \Lambda_{7} & 0 & 0 \\
0 & 0 & 1 & \Lambda_{2} & \Lambda_{4} & \Lambda_{6} & \Lambda_{8} & 0 \\
0 & 0 & 0 & \Lambda_{1} & \Lambda_{3} & \Lambda_{5} & \Lambda_{7} & 0 \\
0 & 0 & 0 & 1 & \Lambda_{2} & \Lambda_{4} & \Lambda_{6} & \Lambda_{8}
\end{array}\right]
$$

For $n e_{1}$ to be asymptotically stable, the principal minors of the above matrix should be positive and this cannot be achieved. It is easy to see that, by plotting the minors against the parameter $k$, there is no interval of $k$, which makes all the minors positive simultaneously. 


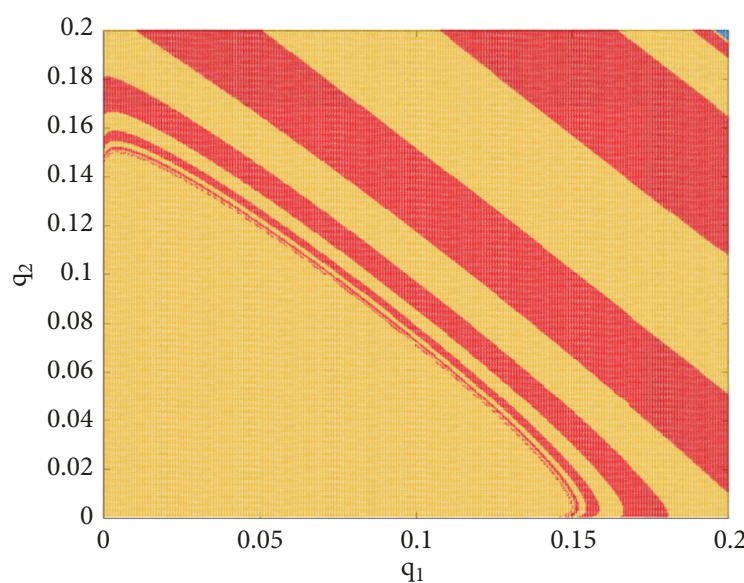

(a)

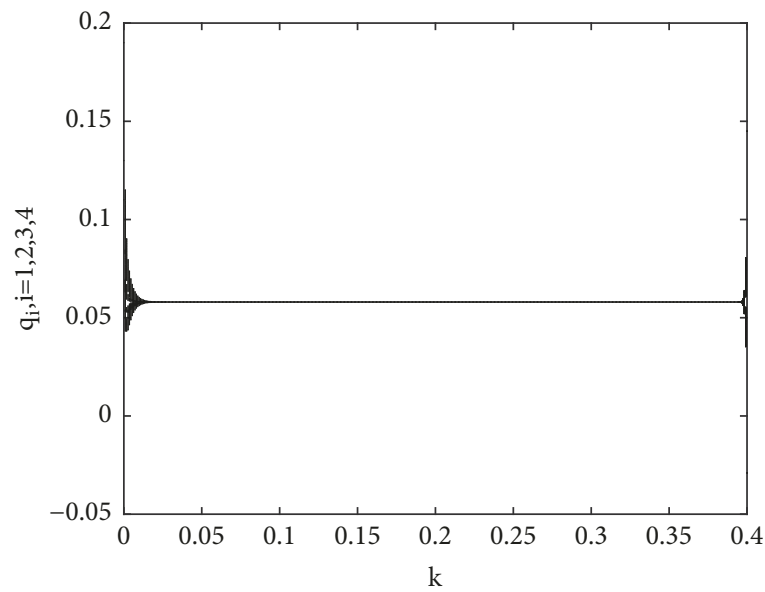

(c)

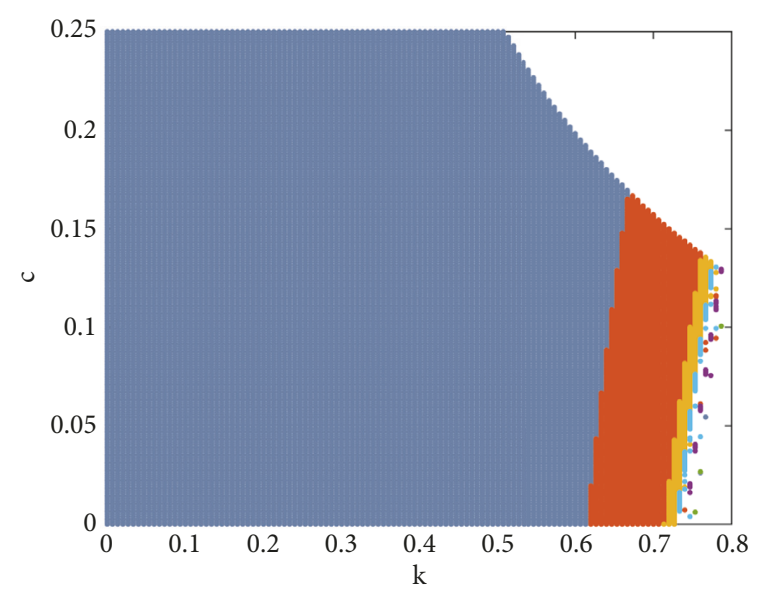

(b)

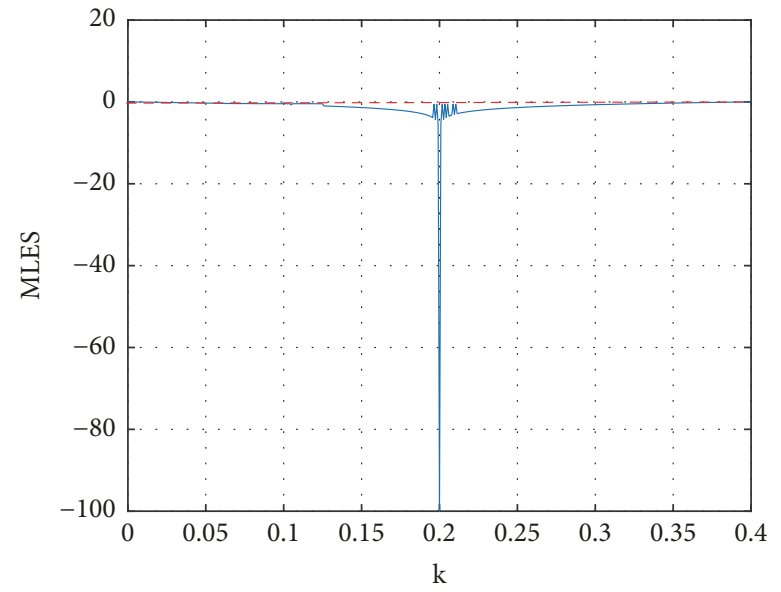

(d)

Figure 5: (a) The basin of attraction of the period 4-cycle at $\left(a, c, k, \alpha, q_{3}, q_{4}\right)=(0.625,0.11,0.75,0.75,0.13,0.11)$. (b) $2 \mathrm{D}$ bifurcation in the $(k, c)$ parameter plane at $\left(a, \alpha, q_{0,1}, q_{0,2}, q_{0,3}, q_{0,4}\right)=(0.625,0.75,0.19,0.15,0.13,0.11)$. (c) Bifurcation diagram of system (6) with respect to $k$ at $\left(a, c, \alpha, q_{0,1}, q_{0,2}, q_{0,3}, q_{0,4}\right)=(0.4,0.11,1,0.19,0.15,0.13,0.11)$. (d) Maximum Lyapunov exponents with respect to $k$ at $\left(a, c, \alpha, q_{0,1}, q_{0,2}, q_{0,3}, q_{0,4}\right)=(0.4,0.11,1,0.19,0.15,0.13,0.11)$.

3.1. Numerical Simulation. Here, the above obtained results are confirmed using some simulations. We assume the following values: $a=1, c=0.11, q_{0,1}=0.19, q_{0,2}=0.15, q_{0,3}=$ $0.13, q_{0,4}=0.11, q_{1,1}=0.3, q_{1,2}=0.4, q_{1,3}=0.5, q_{1,4}=$ 0.6 . Figure 6 shows that the fixed point is not stable for any value of $k$. In addition, the experiments show that the system's stability cannot be detected for any values for the system's parameters. Therefore, adoption of Puu's mechanism does not have any advantages and bounded rationality still does well in this economic competition.

\section{Cooperation Model Based on Keeney-Raiffa Method}

The Keeney-Raiffa function uses a product of objective functions to construct an equivalent mono-objective function. It is similar to the so-called weighted sum (in [35]). In this section, cooperation is studied using the Keeney-Raiffa function. It is assumed that the four firms will cooperate with each other in the market. This means that the Keeney-Raiffa function is given by the following.

$$
\pi_{\text {mono }}=\left(1+\pi_{1}^{2}\right)\left(1+\pi_{2}^{2}\right)\left(1+\pi_{3}^{2}\right)\left(1+\pi_{4}^{2}\right)
$$

Using (2) and (18), one gets the following.

$$
\pi_{\text {mопо }}=\prod_{i=1}^{4}\left(1+\left(a-\sum_{i=1}^{4} q_{i}-c\right)^{2} q_{i}^{2}\right),
$$

$$
i=1,2,3,4
$$

Now, the traditional bounded rationality is applied to investigate the dynamic behavior of the four cooperated firms. This dynamic behavior can be described by a discretetime dynamic system that is obtained using (3) at $\alpha=1$ with (19) as follows. 


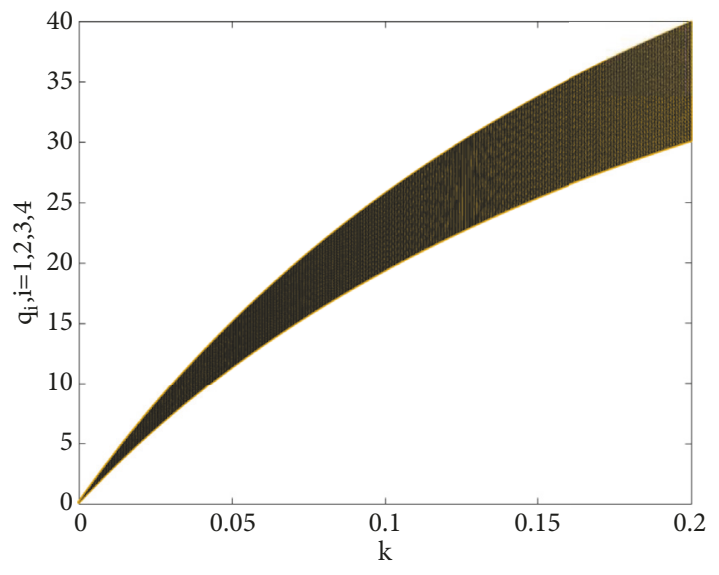

FIGURE 6: Bifurcation diagram of system (14) with respect to $k$ at $\left(a, c, \alpha, q_{0,1}, q_{0,2}, q_{0,3}, q_{0,4}, q_{1,1}, q_{1,2}, q_{1,3}, q_{1,4}\right)=(1,0.11,1,0.19,0.15$, $0.13,0.11,0.3,0.4,0.5,0.6)$.

$$
\begin{aligned}
& q_{1, t+1}=q_{1, t}+2 k q_{1, t}\left(a-\sum_{j=1}^{4} q_{j, t}-c\right) \\
& \cdot\left(a-q_{1, t}-\sum_{j=1}^{4} q_{j, t}-c\right) \\
& \cdot \prod_{i=2}^{4}\left(1+\left(a-\sum_{j=1}^{4} q_{j, t}-c\right)^{2} q_{i, t}^{2}\right) \text {, } \\
& q_{2, t+1}=q_{2, t}+2 k q_{2, t}\left(a-\sum_{j=1}^{4} q_{j, t}-c\right) \\
& \cdot\left(a-q_{2, t}-\sum_{j=1}^{4} q_{j, t}-c\right) \\
& \cdot \prod_{i=1 ; i \neq 2}^{4}\left(1+\left(a-\sum_{j=1}^{4} q_{j, t}-c\right)^{2} q_{i, t}^{2}\right) \text {, } \\
& q_{3, t+1}=q_{3, t}+2 k q_{3, t}\left(a-\sum_{j=1}^{4} q_{j, t}-c\right) \\
& \cdot\left(a-q_{3, t}-\sum_{j=1}^{4} q_{j, t}-c\right) \\
& \cdot \prod_{i=1 ; i \neq 3}^{4}\left(1+\left(a-\sum_{j=1}^{4} q_{j, t}-c\right)^{2} q_{i, t}^{2}\right) \text {, } \\
& q_{4, t+1}=q_{4, t}+2 k q_{4, t}\left(a-\sum_{j=1}^{4} q_{j, t}-c\right) \\
& \cdot\left(a-q_{4, t}-\sum_{j=1}^{4} q_{j, t}-c\right) \\
& \cdot \prod_{i=1}^{3}\left(1+\left(a-\sum_{j=1}^{4} q_{j, t}-c\right)^{2} q_{i, t}^{2}\right)
\end{aligned}
$$

Proposition 5. System (20) has the following fixed points:

(1) $e_{0}=(0,0,0,0), e_{1}=((a-c) / 2,0,0,0), e_{2}=(0,(a-$ c) $/ 2,0,0), e_{3}=(0,0,(a-c) / 2,0), e_{4}=(0,0,0,(a-$ c) $/ 2), e_{5}=((a-c) / 3,(a-c) / 3,0,0), e_{6}=((a-$ c) $/ 3,0,(a-c) / 3,0), e_{7}=((a-c) / 3,0,0,(a-c) / 3), e_{8}=$ $(0,(a-c) / 3,(a-c) / 3,0), e_{9}=(0,(a-c) / 3,0,(a-c) / 3)$, $e_{10}=(0,0,(a-c) / 3,(a-c) / 3), e_{11}=((a-c) / 3,0,(a-$ $c) / 3,0), e_{12}=((a-c) / 4,(a-c) / 4,(a-c) / 4,0), e_{13}=$ $((a-c) / 4,0,(a-c) / 4,(a-c) / 4), e_{14}=(0,(a-c) / 4,(a-$ c) $/ 4,(a-c) / 4)$,

(2) The Nash equilibrium point, ne $=((a-c) / 5,(a-$ c) $/ 5,(a-c) / 5,(a-c) / 5)$.

Due to the difficulty of getting an analytical form of the Jacobian of system (20) at Nash point, some numerical simulations are executed. The simulation begins with the following values for the system's parameters: $\left(a, c, q_{0,1}, q_{0,2}, q_{0,3}, q_{0,4},\right)=(0.7,0.11,0.19,0.15,0.13,0.11)$. Figure 7 (a) presents the bifurcation diagram where the ne point loses its stability at the value $k=14.31$. It is clear that the interval of stability against the parameter $k$ is better than those discussed and obtained previously. This is because of the cooperation admitted among the four firms. The corresponding Lyapunov exponent diagram is shown in Figure 7(b). Consequently, other complex characteristics may coexist. Figure 7(c) shows the 2D bifurcation diagram in the $(k, c)$ plane by which different period cycles can be detected. The basin of attraction of the period 2-cycle and its phase space are given in Figures 7(d) and 8(a). Other period cycles are given in Figures 8(b), 8(c), 8(d), and 9.

\section{Conclusion}

The paper has introduced a competition among four firms using the fractional-order derivatives. The bounded rationality approach has been generalized using Caputo derivative and a new discrete dynamical model has been introduced and discussed in detail. All the model's fixed points have been calculated and only the stability of Nash equilibrium point has been investigated. Some comparisons have been carried out in this paper. Overall, the detailed investigation of the influences of fractional-order parameter and other parameters of the discrete game is presented. It has been observed that the fractional-order parameter plays a destabilizing role in the dynamics of proposed discrete game. In addition, a model of four competed firms with Puu's mechanism has been introduced. The simulation has shown that this model does not guarantee any advantages of Puu's mechanism and the Nash point of this model loses its stability from the beginning for any values of the system's parameters. Furthermore, the assumption of cooperation among the four firms has been introduced and discussed. A mono-profit function has been introduced using Keeney-Raiffa approach to build a discrete dynamic system which has been used in studying the cooperation among the four firms. The simulation has shown that cooperation among the four firms improves the stability of Nash point of the cooperated systems. 


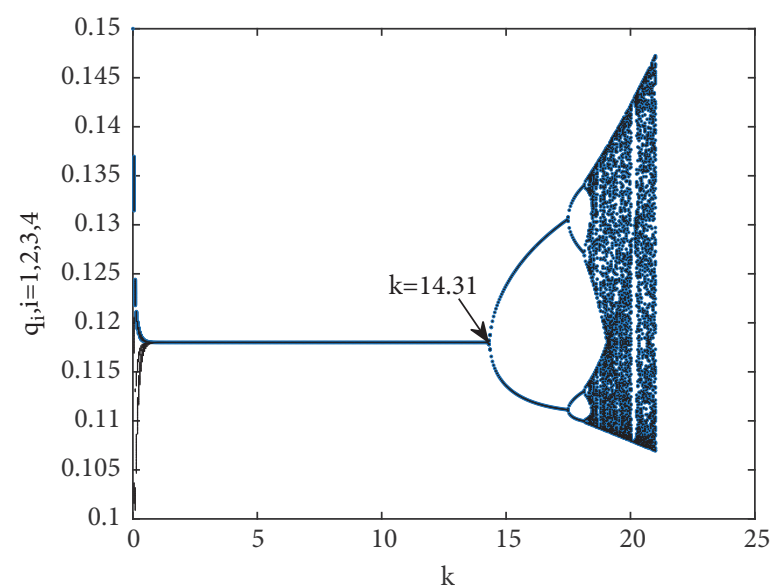

(a)

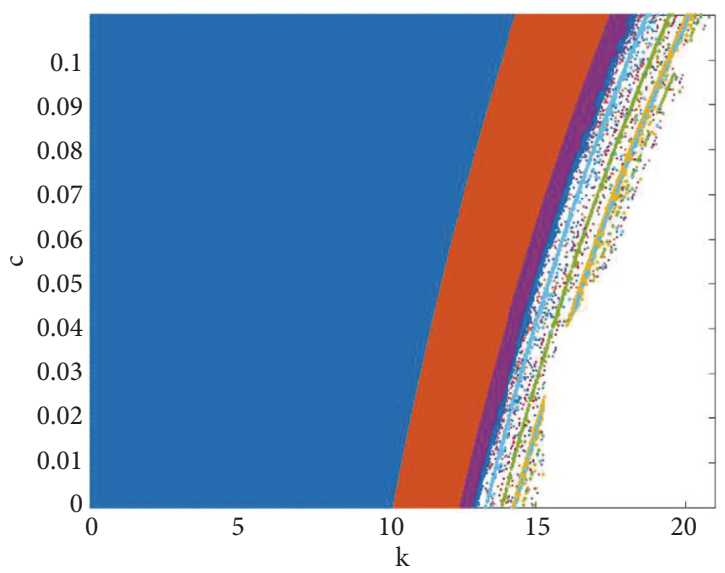

(c)

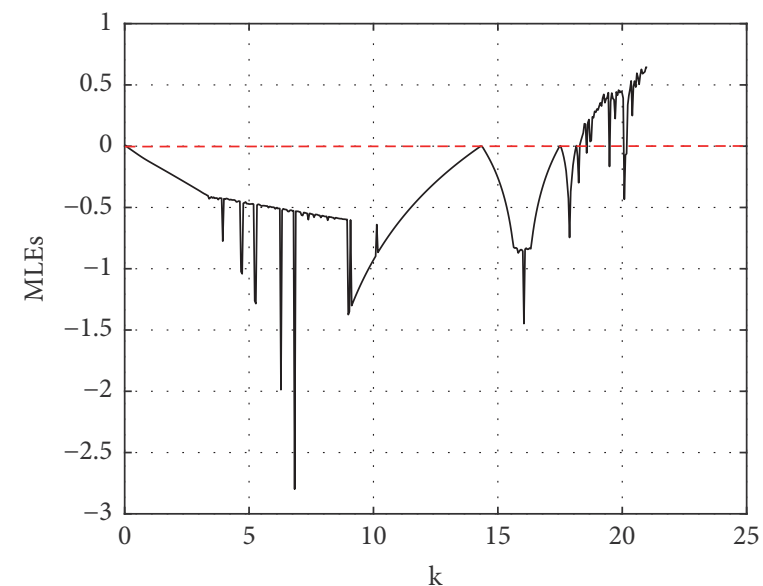

(b)

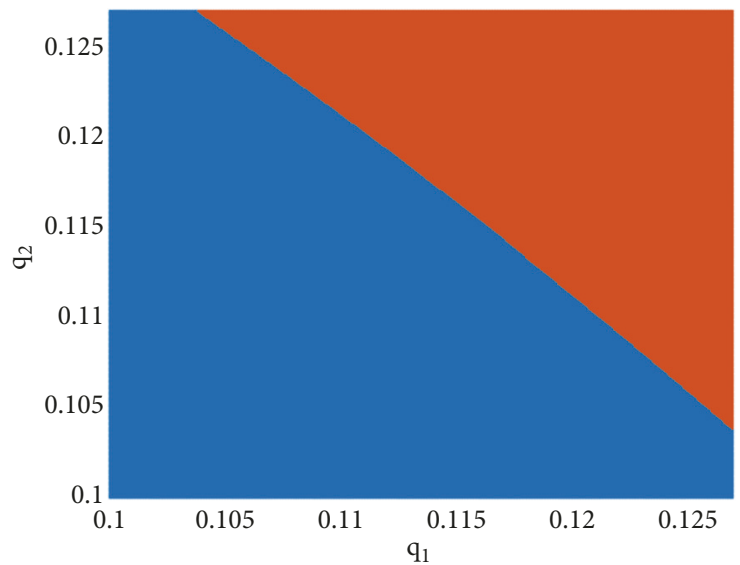

(d)

Figure 7: (a) Bifurcation diagram of system (20) with respect to $k$ at $\left(a, c, q_{0,1}, q_{0,2}, q_{0,3}, q_{0,4},\right)=(0.7,0.11,0.19,0.15,0.13,0.11)$. (b) Maximum Lyapunov exponents with respect to $k$ at $\left(a, c, q_{0,1}, q_{0,2}, q_{0,3}, q_{0,4}\right)=(0.7,0.11,0.19,0.15,0.13,0.11)$. (c) 2D bifurcation in the ( $\left.k, c\right)$ parameter plane at $\left(a, q_{0,1}, q_{0,2}, q_{0,3}, q_{0,4}\right)=(0.7,0.19,0.15,0.13,0.11)$. (d) The basin of attraction of the period 2 -cycle $\left(a, c, k, \alpha, q_{3}, q_{4}\right)=$ $(0.7,0.11,15,0.5,0.13,0.11)$.

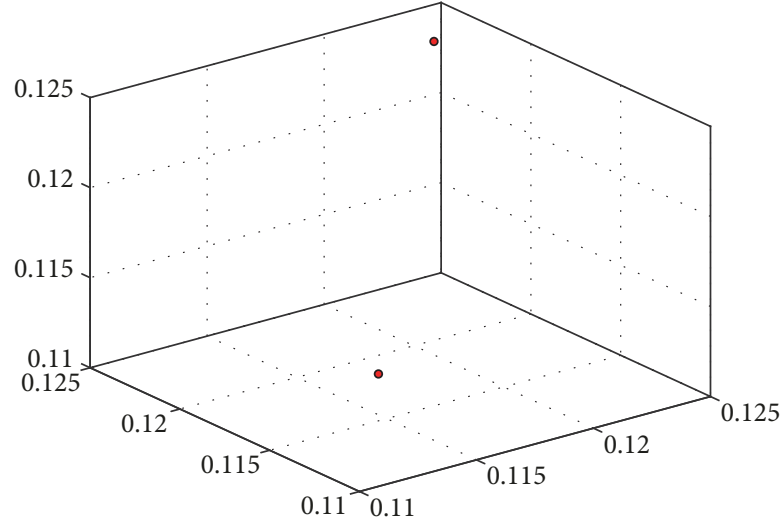

(a)

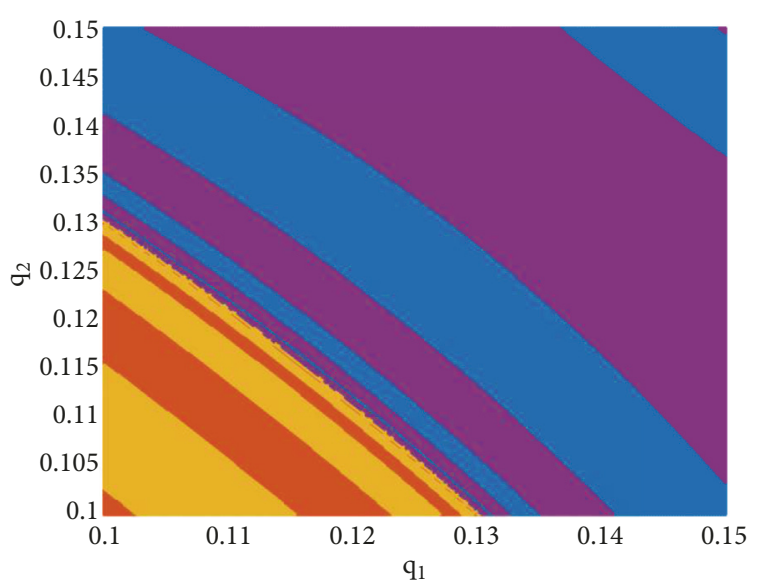

(b)

Figure 8: Continued. 


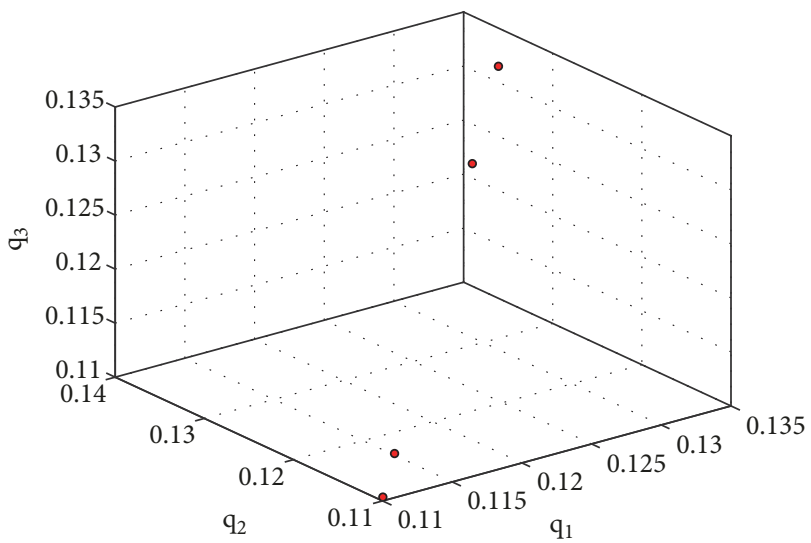

(c)

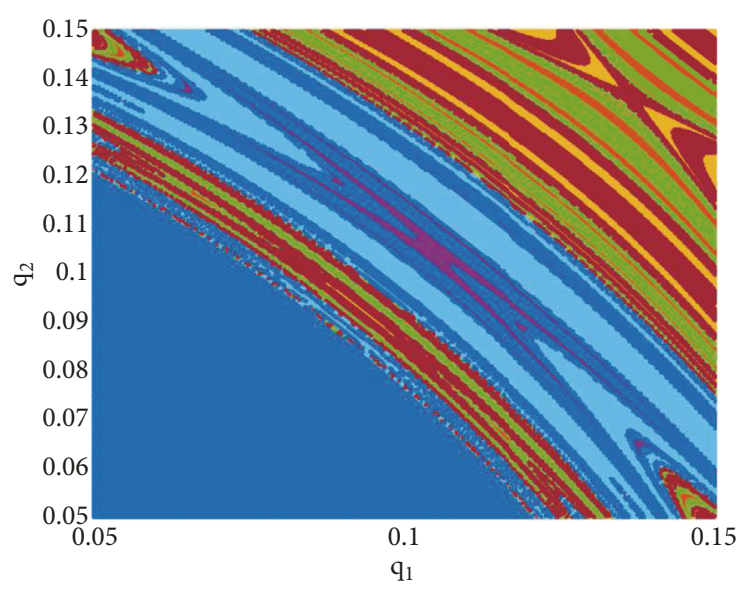

(d)

Figure 8: (a) Phase portrait of the period 2-cycle of system (20) at $\left(a, c, k, \alpha, q_{0,1}, q_{0,2}, q_{0,3}, q_{4}\right)=(0.7,0.11,15,0.19,0.15,0.13,0.11)$. (b) The basin of attraction of the period 4-cycle $\left(a, c, k, \alpha, q_{3}, q_{4}\right)=(0.7,0.11,17.85,0.5,0.13,0.11)$. (c) Phase portrait of the period 4-cycle of system (20) at $\left(a, c, k, \alpha, q_{0,1}, q_{0,2}, q_{0,3}, q_{4}\right)=(0.7,0.11,17.85,0.19,0.15,0.13,0.11)$. (d) The basin of attraction of the period 8 -cycle $\left(a, c, k, \alpha, q_{3}, q_{4}\right)=$ $(0.7,0.11,18.62,0.5,0.13,0.11)$.

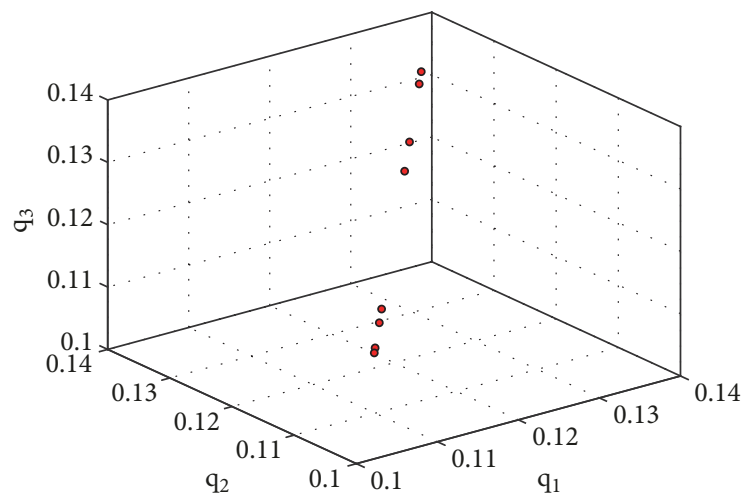

Figure 9: Phase portrait of the period 8-cycle of system (20) at $\left(a, c, k, \alpha, q_{0,1}, q_{0,2}, q_{0,3}, q_{4}\right)=(0.7,0.11,18.26,0.19,0.15,0.13,0.11)$.

\section{Data Availability}

The data used to support the findings of this study have not been made available because it is obtained by using the free software on the Internet that is known as E\&F Chaos software available on https://cendef.uva.nl/software/ef-chaos/ ef-chaos.html?1554748420914.

\section{Disclosure}

The address of S. S. Askar is Department of Mathematics, Faculty of Science, Mansoura University, Mansoura 35516, Egypt.

\section{Conflicts of Interest}

The authors declare that they have no conflicts of interest regarding the content of this article.

\section{Acknowledgments}

The authors would like to extend their sincere appreciation to the Deanship of Scientific Research at King Saud University for funding this research (group No. RG-1435-054).

\section{References}

[1] V. E. Tarasov, Fractional Dynamics: Application of Fractional Calculus to Dynamics of Particles, Fields and Media, Springer, New York, NY, USA, 2010.

[2] G. Teyssiere and A. P. Kirman, Long Memory in Economics, Springer, Berlin, Heidelberg, Germany, 2007.

[3] V. E. Tarasov and V. V. Tarasova, "Long and short memory in economics: fractional-order difference and differentiation," IRA-International Journal of Management and Social Sciences, vol. 5, no. 2, pp. 327-334, 2016.

[4] J. V. Neumann and O. Morgenstern, Theory of Games and Economic Behavior, Princeton University Press, Princeton, NJ, USA, 1944.

[5] J. F. Nash Jr., “The bargaining problem,” Econometrica, vol. 18, pp. 155-162, 1950.

[6] L. S. Shapley, "A value for n-person games," in Contributions to The Theory of Games, H. Kuhn and A. W. Tucker, Eds., vol. II, pp. 307-317, Princeton University Press, 1953.

[7] D. A. Freedman, Game Theory with Applications to Economics, Oxford University Press, Cambridge, UK, 1990.

[8] A. Mas-Colell, "An equivalence theorem for a bargaining set," Journal of Mathematical Economics, vol. 18, no. 2, pp. 129-139, 1989.

[9] S. Hart, "Non-zero-sum two-person repeated games with incomplete information," Mathematics of Operations Research, vol. 10, no. 1, pp. 117-153, 1985.

[10] J. Andaluz and G. Jarne, "On the dynamics of economic games based on product differentiation," Mathematics and Computers in Simulation, vol. 113, pp. 16-27, 2015. 
[11] C. Hommes, Behavioral Rationality and Heterogeneous Expectations in Complex Economic Systems, Cambridge University Press, Cambridge, UK, 2013.

[12] H. N. Agiza and A. A. Elsadany, "Chaotic dynamics in nonlinear duopoly game with heterogeneous players," Applied Mathematics and Computation, vol. 149, no. 3, pp. 843-860, 2004.

[13] S. S. Askar, "Tripoly Stackelberg game model: one leader versus two followers," Applied Mathematics and Computation, vol. 328, pp. 301-311, 2018

[14] S. S. Askar, A. M. Alshamrani, and K. Alnowibet, "The arising of cooperation in Cournot duopoly games," Applied Mathematics and Computation, vol. 273, pp. 535-542, 2016.

[15] S. S. Askar, M. F. EL-Wakeel, and M. A. Alrodaini, "Exploration of complex dynamics for cournot oligopoly game with differentiated products," Complexity, vol. 2018, Article ID 6526794, 13 pages, 2018.

[16] H. N. Agiza and A. A. Elsadany, "Nonlinear dynamics in the Cournot duopoly game with heterogeneous players," Physica A: Statistical Mechanics and its Applications, vol. 320, pp. 512-524, 2003.

[17] J. Ma and X. Pu, "The research on Cournot-Bertrand duopoly model with heterogeneous goods and its complex characteristics," Nonlinear Dynamics, vol. 72, no. 4, pp. 895-903, 2013.

[18] J. Ma and K. Wu, "Complex system and influence of delayed decision on the stability of a triopoly price game model," Nonlinear Dynamics, vol. 73, no. 3, pp. 1741-1751, 2013.

[19] A. Agliari, A. K. Naimzada, and N. Pecora, "Nonlinear dynamics of a cournot duopoly game with differentiated products," Applied Mathematics and Computation, vol. 281, pp. 1-15, 2016.

[20] L. Gori and M. Sodini, "Price competition in a nonlinear differentiated duopoly," Chaos, Solitons \& Fractals, vol. 104, pp. 557-567, 2017.

[21] A. K. Naimzada and R. Raimondo, "Chaotic congestion games," Applied Mathematics and Computation, vol. 321, pp. 333-348, 2018.

[22] S. S. Askar, A. M. Alshamrani, and K. Alnowibet, "Dynamic cournot duopoly games with nonlinear demand function," Applied Mathematics and Computation, vol. 259, pp. 427-437, 2015.

[23] S. S. Askar, "Chaotic behavior of monoploy model," Journal of Computational and Theoretical Nanoscience, vol. 13, no. 1, pp. 15, 2015.

[24] S. S. Askar, "The rise of complex phenomena in Cournot duopoly games due to demand functions without inflection points," Communications in Nonlinear Science and Numerical Simulation, vol. 19, no. 6, pp. 1918-1925, 2014.

[25] P. Grigolini, N. Piccinini, A. Svenkeson, P. Pramukkul, D. Lambert, and B. J. West, "From neural and social cooperation to the global emergence of cognition," Frontiers in Bioengineering and Biotechnology, vol. 3, no. 78, pp. 1-15, 2015.

[26] K. Mahmoodi, B. J. West, and P. Grigolini, "Self-organized temporal criticality: bottom-up resilience versus top-down vulnerability," Complexity, vol. 2018, Article ID 8139058, 10 pages, 2018.

[27] M. Bologna, B. J. West, and P. Grigolini, "Renewal and memory origin of anomalous diffusion: A discussion of their joint action," Physical Review E: Statistical, Nonlinear, and Soft Matter Physics, vol. 88, Article ID 062106, 2013.

[28] K. Mahmoodi, B. J. West, and P. Grigolini, "Self-organizing complex networks: Individual versus global rules," Frontiers in Physiology, vol. 8, article no. 478, 2017.
[29] J. Qin, Y. Chen, Y. Kang, and M. Perc, "Social diversity promotes cooperation in spatial multigames," EPL (Europhysics Letters), vol. 118, no. 1, 2017.

[30] S. S. Askar, "On complex dynamics of monopoly market," Economic Modelling, vol. 31, no. 1, pp. 586-589, 2013.

[31] S. S. Askar and A. Alshamrani, "The dynamics of economic games based on product differentiation," Journal of Computational and Applied Mathematics, vol. 268, pp. 135-144, 2014.

[32] S. S. Askar and M. F. Elettreby, "The impact of cost uncertainty on Cournot oligopoly games," Applied Mathematics and Computation, vol. 312, pp. 169-176, 2017.

[33] H. Podlubny, Fractional Differential Equations, Academic Press, New York, NY, USA, 1999.

[34] S. S. Askar and M. Abouhawwash, "Quantity and price competition in a differentiated triopoly: static and dynamic investigations," Nonlinear Dynamics, vol. 91, no. 3, pp. 1963-1975, 2018.

[35] Y. Collette and P. Siarry, Multi-Objective Optimization: Principles and Case Studies, Springer, Berlin, Germany, 2003. 


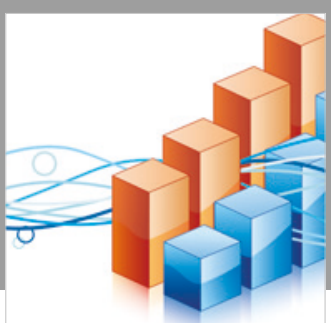

Advances in

Operations Research

\section{-n-m}
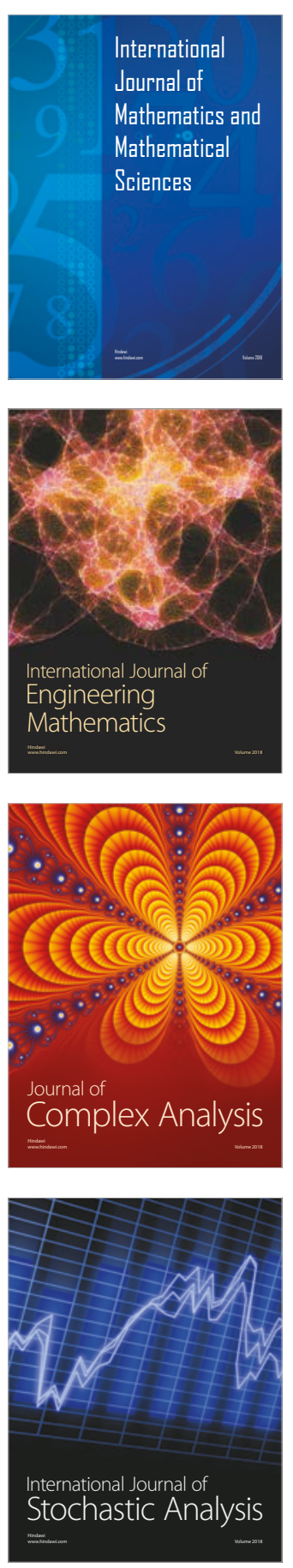
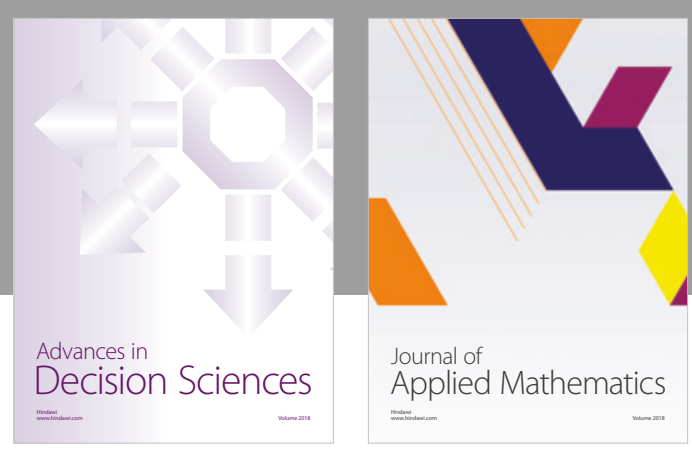

Journal of

Applied Mathematics
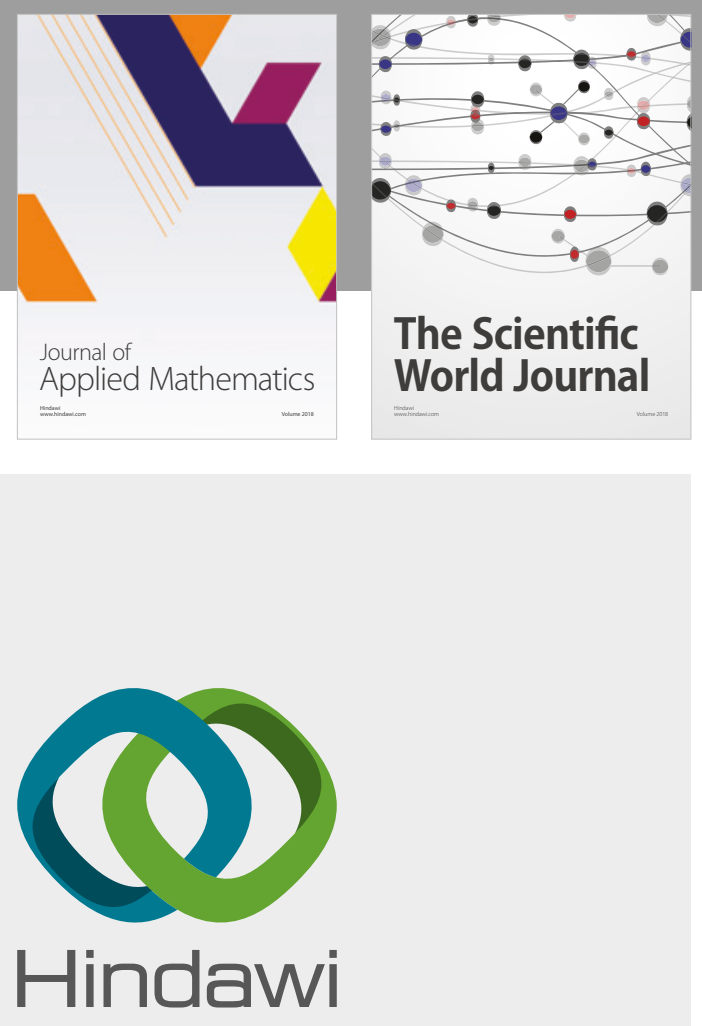

Submit your manuscripts at

www.hindawi.com

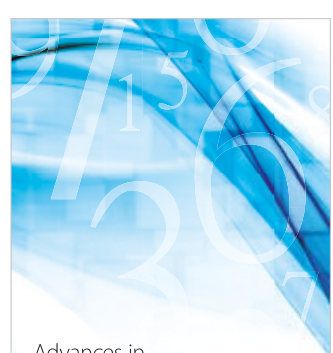

Advances in
Numerical Analysis
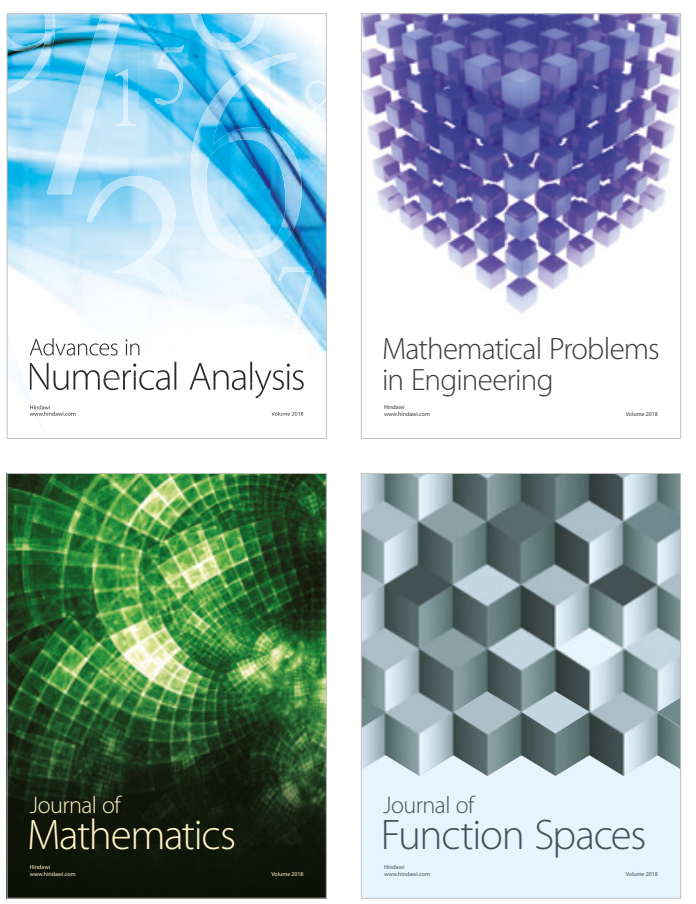

Mathematical Problems in Engineering

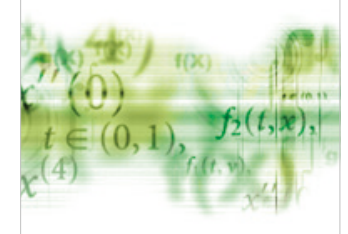

International Journal of

Differential Equations

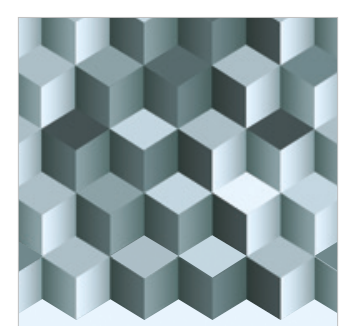

Journal of

Function Spaces
The Scientific

World Journal

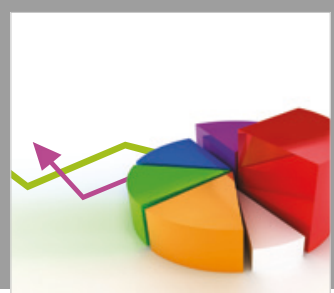

Journal of

Probability and Statistics
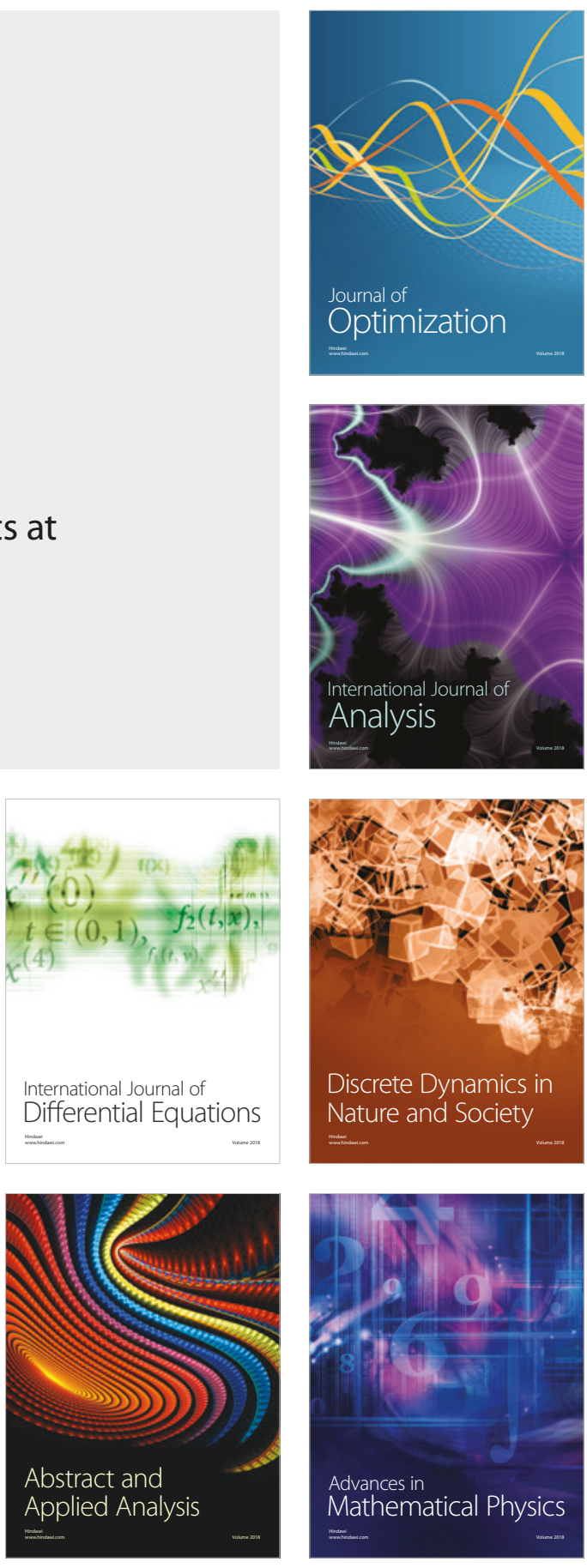